\title{
Quaternary prevention: first, do not harm
}

\author{
Prevenção quaternária: primeiro não causar dano
}

\section{Prevención cuaternaria: primero no hacer daño}

Marc Jamoulle. MD, Family doctor, Freelance researcher in Primary Care. Department of General Practice, University of Liège, Liège, Belgium. Member of the Wonca International Classification Committee. marc.jamoulle@doct.ulg.ac.be (Corresponding author)

\section{Towards patient-doctor relationship based care}

Clinical prevention, under the influence of public health, has been organised in a chronological manner since the middle of the $20^{\text {th }}$ century. A paradigm shift from a chronological to a constructivist relationship-based preventive pattern of care $^{1}$ offers new insights into the practice of doctors. This paradigm shift brings to light the concept of quaternary prevention, a critical look at medical activities with an emphasis on the need not to harm. Quaternary prevention addresses the fundamental question of what constitutes too much or too little medicine. It is the fourth form of disease prevention, but also the fourth frame of action for family doctors (Figure 1).

The shift from time-based prevention towards a relationship-based organisation offers new perspectives into physicians' work. The physicians observe themselves and question the ethical limits of their activities. In this sense, quaternary prevention is aimed more at the doctor than the patient. Moreover, the four definitions of prevention, published in the Wonca Dictionary of Family Medicine, ${ }^{2}$ offer a structured way to discuss the activities of family doctors, including ethical considerations on the patient-doctor encounter. Quaternary prevention, also known as $\mathrm{P} 4$, is a new term for an old concept: first, do not harm. This concept enforces disciplines and attitudes such as evidence-based medicine, quality assurance, defensive medicine, avoiding abusive nosographic diagnoses and ethical issues including those linked to overinformation, and overmedicalisation. ${ }^{3}$

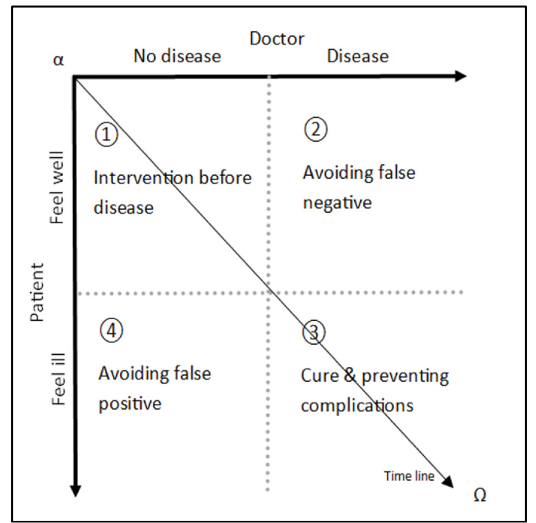

Figure 1. Four fields of the patient-doctor encounter based on relationships. The doctor looks for diseases. The patient could feel ill. Timeline is obliquely oriented from left to right, from alpha to omega, from birth to death. Anyone will become sick and die, doctors as well as patients. 


\section{Quaternary prevention concept expanding worldwide}

Disseminated by the colleagues of the Wonca International Classification Committee (WICC), the P4 concept is now widely recognised in Europe, Canada, South America and Asia. Astonishingly, quaternary prevention has lain dormant for two decades. With the expansion of Internet and social networks and facing the worldwide overdiagnosis movement, family doctors are now recently jostled with the idea. Endorsed by the Brazilian Society of Family and Community Medicine (SBMFC), Quaternary prevention has been proposed as a core concept of the Brazilian National Health System ${ }^{4}$ and has induced an international movement in the whole South America. Following the Quaternary Prevention Workshop during the Wonca Europe Basel Conference in 2010, the Swiss Journal of Primary Care has published a paper on P4 in six languages. ${ }^{5}$ During the Wonca World Conference in Prague, in 2013, a P4 seminar was organised with speakers from New Zealand, China, Iran, the UK and Belgium ${ }^{6}$ and a poster was translated into French, Spanish, Portuguese, Vietnamese, Thai and Chinese, ${ }^{7}$ followed by a publication in the Hong Kong journal of general practitioners. ${ }^{8}$ In addition, during the recent Lisbon Wonca conference, in 2014, the tiny room was crowded of enthusiastic young doctors while the Wonca past president Richard Roberts was presenting the P4 concept as seminal for the future of Wonca (Figure 2).

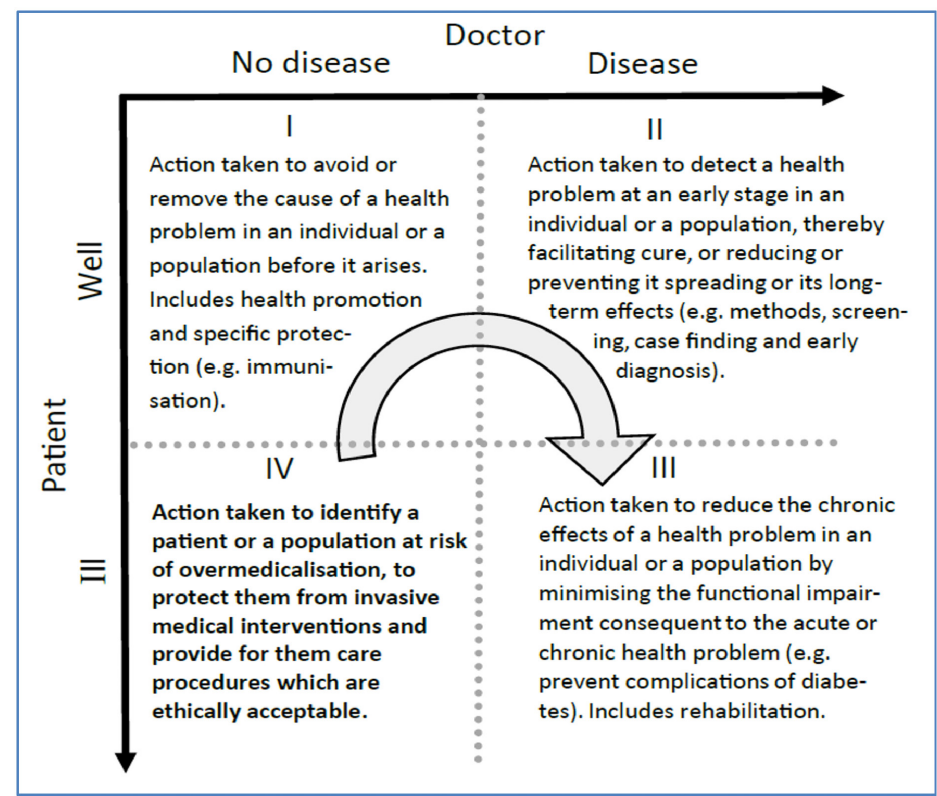

Figure 2. The patient-doctor relationship is at the origin of the four types of activities. The arrow shows that the P4 attitude is impacting all the activities. 1,2

The enthusiasm generated around this topic shows that the P4 concept is used as a framework for a multifaceted repositioning of current questions and limitations of medical practice: disease invention, Attention Deficit Hyperactivity Disorder (ADHD) market extension, transformation of symptoms into diseases, osteoporosis marketing, breast cancer epidemiology and screening, incidentaloma issues, flu immunization, HPV, drug marketing, as well as empathy and communication, the value of the symptoms, rational use of drugs (including antibiotics), and the cautious drug use in mental health, hypertension or dyslipidaemia. And this list is not exhaustive.

Quaternary prevention involves the need for close monitoring by the doctor himself, a sort of permanent quality control on behalf of the consciousness of the harm they could do, even unintentionally, to their patients. Quaternary prevention is also about understanding that medicine is based on a relationship, and that this relation must remain truly therapeutic by respecting the autonomy of patients and doctors. P4 attitude acts as a resistance, a rallying cry against the lack of humanity of whole sectors of medicine and their institutional corruption. 


\section{A growing P4 network}

The P4 network has now members in Brazil, Argentina, Uruguay, Bolivia, Ecuador, Peru, Canada, Pakistan, China, India, Thailand, Vietnam, Belgium, France, Germany, Italy, Spain and England, expressing through websites, Facebook and Twitter. After the 2013 Curitiba Meeting in Brazil, members of the Brazilian P4 group have written The Curitiba Manifesto: for the Quaternary Prevention and for a Medical Practice without conflicts of interest. ${ }^{9}$ For more information about quaternary prevention-related events as well as links, bibliography and slides, access the Wonca International Classification Committee website under the Quaternary Prevention rubric.

\section{References}

1. Jamoulle M. Information et informatisation en médecine générale [Computer and computerisation in general practice]. In: Les informa-g-iciens. Presses Un. Namur, Belgium: Presses Universitaires de Namur; 1986:193-209.

2. Bentzen N. Wonca Dictionary of General/Family Practice. Maanedsskr. Copenhagen; 2003.

3. Jamoulle M. Quaternary prevention, an answer of family doctors to overmedicalization. Int J Health Policy Manag. 2015;4(2):61-64. http://dx.doi.org/10.15171/ijhpm.2015.24. PMid:25674569. PMCid:PMC4322627

4. Norman AH, Tesser CD. Prevenção quaternária na atenção primária à saúde: uma necessidade do Sistema Único de Saúde [Quaternary prevention in primary care: a necessity for the Brazilian Unified National Health System]. Cad Saúde Pública / Ministério Da Saúde, Fundação Oswaldo Cruz, Esc Nac Saúde Pública. 2009;25(9):2012-2020. Available at: http://www.ncbi.nlm.nih.gov/pubmed/19750388

5. Kuehlein T, Sghedoni D, Visentin G, et al. Quaternary prevention: a task of the general practitioner. Prim Care 2010. 18:350-4. http://www.primary-care.ch/docs/primarycare/archiv/fr/2010/2010-18/2010-18-368_ELPS_engl.pdf

6. Jamoulle M, Tsoi G, Heath I, Mangin D, Pezeshki M, Pizzanelli Báez M. Quaternary prevention, addressing the limits of medical practice. Wonca world conference Prague 2013 Retrieved from http://www.ph3c.org/PH3C/docs/27/000322/0000469.pdf

7. Jamoulle M, \& Roland M. Quaternary prevention. From Wonca world Hong Kong 1995 to Wonca world Prague 2013. In Wonca world conference Prague 2013 (Poster). Retrieved from http://www.ph3c.org/PH3C/docs/27/000284/0000435.pdf

8. Tsoi G. Quaternary prevention (editorial). Hong Kong Pract. 2014;36(June):49-50.

9. Silva AL, Mangin D, Pizzanelli M, Jamoulle M, Wagner HL, Silva DH et al. Manifesto de Curitiba: pela Prevenção Quaternária e por uma Medicina sem conflitos de interesse. Rev Bras Med Fam Comunidade. 2014;9(33):371-374. Disponível em http://dx.doi.org/10.5712/ rbmfc9(32)1006. 